\title{
Successful Surgical Repair of Anterior Rectocele in Patient With Constipation
}

\author{
Ki Su Kim, ${ }^{1}$ Moo In Park, ${ }^{1 *}$ Sung Eun Kim ${ }^{1}$ and Seung-Hyun Lee ${ }^{2}$ \\ Departments of ${ }^{1}$ Internal Medicine and ${ }^{2}$ Surgery, Kosin University College of Medicine, Busan, Korea
}

A 56-year-old female visited our department because of the constipation over 30 years. In addition, intermittent cramping abdominal pain was combined in recent 6 months. Despite of the combination of prokinetics, bulking agents and osmotic laxatives, the frequency of defecation was about once every 4 to 7 days, and she performed digital vaginal pressure to defecate. Laboratory findings, plain abdominal radiography, colonoscopy and abdominal computed tomography were unremarkable. Colon transit time was within the normal range.

Eventually, about $5 \mathrm{~cm}$ sized anterior rectocele was detected on fluoroscopic defecography (Figure A and D). We treated with medication and biofeedback therapy. However, constipation was not improved for 6 months and even the size of rectocele was increased to $5.5 \mathrm{~cm}$ on the follow-up defecography (Figure B and E). Therefore, she underwent rectocele repair with colporrhaphy. About 6 months after surgery, the size of rectocele was decreased to $2 \mathrm{~cm}$ on follow-up defecography (Figure $\mathrm{C}$ and $\mathrm{F}$ ). When we evaluated symptom response before and after the surgery using Birmingham Bowel and Urinary Symptoms Questionnaire (BBUSQ-22), ${ }^{1,2}$ the score of constipation and evacuation was decreased. And, she could defecate daily without abdominal pain.

Rectocele is a herniation of the rectal wall that often becomes apparent during defecation. Rectocele is common in adult women (20\%), and most of it is small $(<2 \mathrm{~cm})$, asymptomatic, therefore treatment is not necessary. However, surgery is suitable for patients in whom large rectocele ( $>3$ or $4 \mathrm{~cm}$ ) or those with coexisting vaginal prolapse is present in spite of adequate medication. ${ }^{3}$ Thus, surgical treatment could be considered in some patients with rectocele.

\section{References}

1. Hiller L, Radley S, Mann CH, et al. Development and validation of a questionnaire for the assessment of bowel and lower urinary tract symptoms in women. BJOG 2002;109:413-423.

2. Hiller L, Bradshaw HD, Radley SC, Radley S. Scoring system for the assessment of bowel and lower urinary tract symptoms in women. BJOG 2002;109:424-430.

3. Schey R, Cromwell J, Rao SS. Medical and surgical management of pelvic floor disorders affecting defecation. Am J Gastroenterol 2012; 107:1624-1633.

Received: January 2, 2013 Revised: April 12, 2013 Accepted: April 15, 2013

(c) This is an Open Access article distributed under the terms of the Creative Commons Attribution Non-Commercial License (http://creativecommons. org/licenses/by-nc/3.0) which permits unrestricted non-commercial use, distribution, and reproduction in any medium, provided the original work is properly cited.

*Correspondence: Moo In Park, MD

Department of Internal Medicine, Kosin University College of Medicine, 262, Gamcheon-ro, Seo-gu, Busan 602-702, Korea

Tel: +82-51-990-6719, Fax: +82-51-990-5055, E-mail: mipark@ns.kosinmed.or.kr

Financial support: None.

Conflicts of interest: None. 

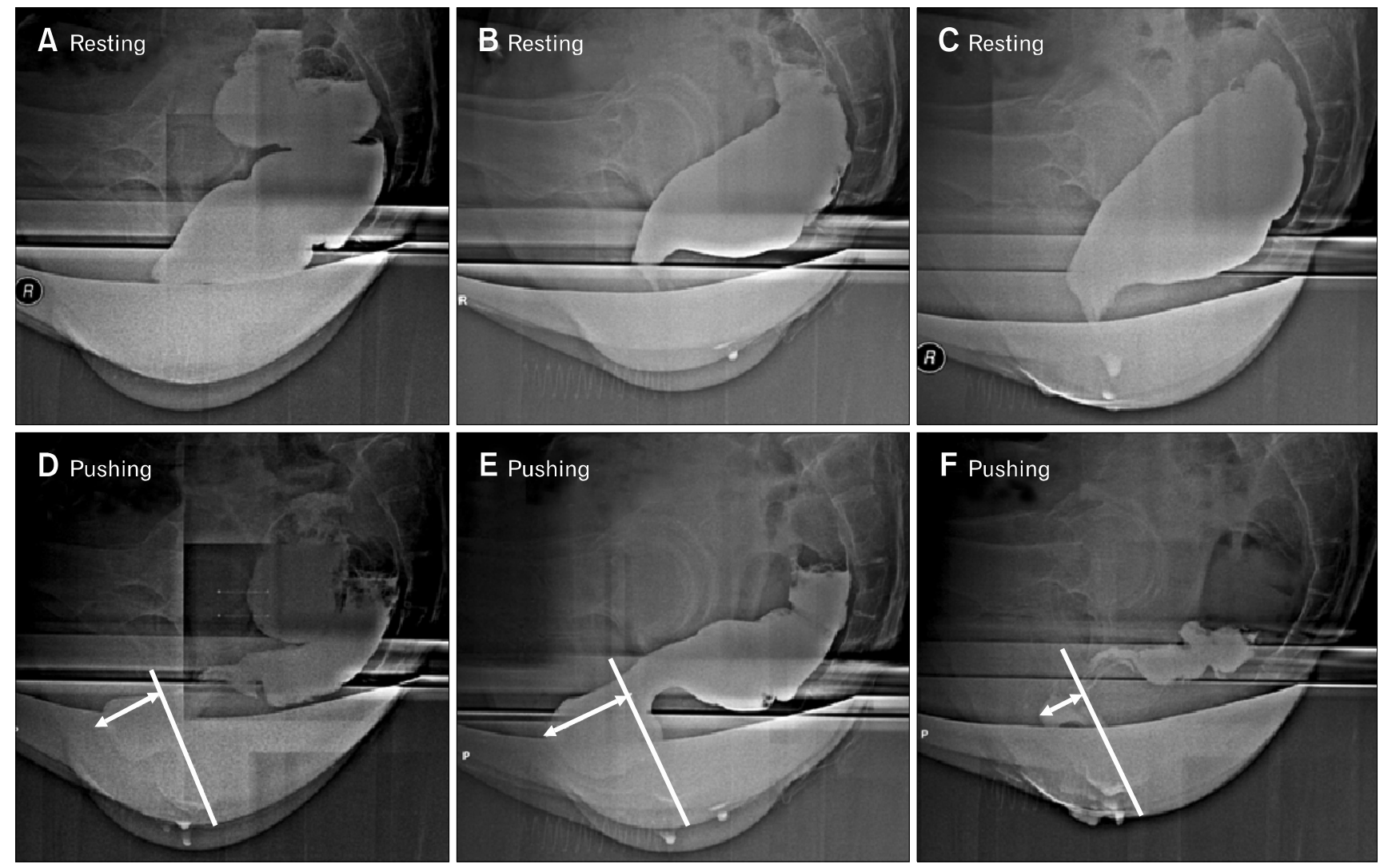

Figure. Fluoroscopic defecography. The measured size of rectocele (white arrow) is perpendicular to the axis of the anal canal (white line). (A) Initial image of the resting phase. (B) The resting phase image after 6 months. (C) The resting phase image after surgery. (D) About $5 \mathrm{~cm}$ sized large anterior rectocele was observed at initial pushing phase. (E) The size of anterior rectocele was increased in 6 months (about $5.5 \mathrm{~cm}$ ). (F) The size of rectocele was decreased after surgery (about $2 \mathrm{~cm}$ ). 